\title{
Strength training induced adaptations in neuromuscular function of premenopausal women with fibromyalgia: comparison with healthy women
}

\author{
A Häkkinen, K Häkkinen, P Hannonen, M Alen
}

\begin{abstract}
Objective-To investigate the effects of 21 weeks' progressive strength training on neuromuscular function and subjectively perceived symptoms in premenopausal women with fibromyalgia (FM).

Methods-Twenty one women with FM were randomly assigned to experimental $\left(\mathbf{F M}_{\mathrm{T}}\right)$ or control $\left(\mathbf{F} \mathbf{M}_{\mathrm{C}}\right)$ groups. Twelve healthy women served as training controls $\left(H_{\mathrm{T}}\right)$. The $F M_{\mathrm{T}}$ and $\mathrm{H}_{\mathrm{T}}$ groups carried out progressive strength training twice a week for 21 weeks. The major outcome measures were muscle strength and electromyographic (EMG) recordings. Secondary outcome measures were pain, sleep, fatigue, physical function capacity (Stanford Health Assessment Questionnaire), and mood (short version of Beck's depression index).

Results-Female $\mathbf{F M}_{\mathrm{T}}$ subjects increased their maximal and explosive strength and EMG activity to the same extent as the $\mathrm{H}_{\mathrm{T}}$ group. Moreover, the progressive strength training showed immediate benefits on subjectively perceived fatigue, depression, and neck pain of training patients with FM. Conclusions-The strength training data indicate comparable trainability of the neuromuscular system of women with FM and healthy women. Progressive strength training can safely be used in the treatment of FM to decrease the impact of the syndrome on the neuromuscular system, perceived symptoms, and functional capacity. These results confirm the opinion that FM syndrome has a central rather than a peripheral or muscular basis. (Ann Rheum Dis 2001;60:21-26)
\end{abstract}

Fibromyalgia (FM) is a non-inflammatory rheumatic syndrome characterised by widespread musculoskeletal pain with palpable tender points, muscle stiffness, fatigue, and sleep disturbances. ${ }^{1}$ The cause of symptoms has remained an enigma and the treatment problematic. Opinions are divided about the pathogenetic role of a peripheral versus a central mechanism. A number of studies of muscle histology and energy metabolism have been conducted to increase the understanding of the origin of FM symptoms. Some studies suggest a possible pathological basis in muscle tissue, ${ }^{2-4}$ whereas others report that the muscles of patients with FM do not differ from those of healthy controls. ${ }^{56}$ On the other hand, although treatment with glucocorticoids, ${ }^{7}$ non-steroidal anti-inflammatory drugs, ${ }^{8}$ muscle relaxants, ${ }^{9}$ hypnotic drugs, ${ }^{10}{ }^{11}$ and modern antidepressant drugs $^{12-14}$ is of little help, the use of low dose tricyclic antidepressant drugs has proved effective in a proportion of patients with FM..$^{814}$

Exercise interventions are often included in rehabilitation programmes of patients with FM. A number of earlier studies have examined the effects of aerobic exercise, ${ }^{16-18}$ relaxation programmes, ${ }^{19}{ }^{20}$ or combinations of them in multidimensional approaches $\mathrm{s}^{21-23}$ and reported training induced benefits in FM. Although muscular pain is a general feature of FM syndrome, to our knowledge, the effects of strength training on it have been studied only in a six week study as a part of an aerobic, flexibility, and strengthening programme. ${ }^{21}$

The main purpose of our study was to investigate the effects of a prolonged period of 21 weeks' progressive strength training on neuromuscular function in premenopausal women with FM compared with healthy women. In addition, the subjectively perceived symptoms in women with FM were recorded before and after the training period.

\section{Methods}

STUDY SUBJECTS

Twenty one premenopausal women with FM from our outpatient clinic were recruited for the study. Before inclusion the patients were examined by a rheumatologist $(\mathrm{PH})$ to confirm the diagnosis of FM according to the 1990 American College of Rheumatology classification criteria. ${ }^{24}$ After inclusion the patients were randomly allocated to the training $\left(\mathrm{FM}_{\mathrm{T}}\right.$; $\mathrm{n}=11)$ or control $\left(\mathrm{FM}_{\mathrm{C}} ; \mathrm{n}=10\right)$ group. Twelve sedentary healthy women served as training controls $\left(\mathrm{H}_{\mathrm{T}}\right)$. Table 1 shows demographic data of the study groups.

MUSCLE STRENGTH MEASUREMENTS

A David-210 dynamometer was used to measure maximal voluntary bilateral concentric

Table 1 Demographic data of the groups studied: training women with fibromyalgia $\left(F M_{T}\right)$, training healthy women $\left(H_{T}\right)$, and non-training women with fibromyalgia $\left(F M_{C}\right)$. Values are means (SD)

\begin{tabular}{|c|c|c|c|}
\hline & $\begin{array}{l}F M_{T} \\
(n=11)\end{array}$ & $\begin{array}{l}F M_{C} \\
(n=10)\end{array}$ & $\begin{array}{l}H_{T} \\
(n=12)\end{array}$ \\
\hline Age (years) & $39(6)$ & $37(5)$ & $37(6)$ \\
\hline Height $(\mathrm{cm})$ & $165(6)$ & $164(6)$ & $162(5)$ \\
\hline \multicolumn{4}{|l|}{ Weight (kg): } \\
\hline Before & $70(10)$ & $72(16)$ & $63(8)$ \\
\hline After & $70(10)$ & $72(16)$ & $64(8)$ \\
\hline \multicolumn{4}{|l|}{ Fat $(\%)$ : } \\
\hline Before & $34(4)$ & $32(7)$ & $32(4)$ \\
\hline After & $33(4)$ & $32(7)$ & $31(5)$ \\
\hline \multicolumn{4}{|l|}{ Number of tender points: } \\
\hline Before & $16(2)$ & $15(2)$ & \\
\hline After & $15(4)$ & $16(2)$ & \\
\hline Duration of symptoms (years) & $12(4)$ & $12(10)$ & \\
\hline
\end{tabular}

Accepted for publication 26 April 2000 
force production of the leg extensors (hip, knee, and ankle extensors). ${ }^{25}$ The subject was in a seated position so that the hip angle was $110^{\circ}$. On verbal command the subject performed a concentric leg extension starting from a flexed position of $70^{\circ}$ trying to reach a full extension of $180^{\circ}$ against resistance. After each separate extension the load was gradually increased until the subject was unable to extend the legs to the required position. The last acceptable trial with the heaviest load was determined as one repetition maximum (1 $\mathrm{RM}$ ). Low resistance warm up sets were conducted before $1 \mathrm{RM}$ strength testing so that the subjects would be familiar with the equipment and the proper exercise techniques. The first four weeks of the study served as a control period without strength training. The training subjects were assessed four weeks before training, at the start of training, and after 7,14 , and 21 weeks of training. The control subjects with FM were measured at weeks $-4,0$, and 21 .

Maximal voluntary bilateral isometric force and maximal rate of rise of force development (RFD) of the leg extensors were measured using a dynamometer reported earlier. ${ }^{25}$ RFD was used as an isometric measure of explosive strength of the leg extensors. Maximal unilateral isometric force of the knee flexors was measured with a David-200 dynamometer. ${ }^{26}$ The subject was in a seated position with hip and knee joints at $110^{\circ}$ and $107^{\circ}$ angles, respectively. On verbal command the subjects were instructed to exert their maximal force as fast as possible for a period of three to four seconds. A minimum of three trials was completed for each subject and the best result used for the subsequent statistical analysis.

\section{ELECTROMYOGRAPHIC RECORDINGS}

Electromyographic (EMG) activity during the bilateral isometric extension actions of the leg muscles was recorded from vastus lateralis, vastus medialis, and biceps femoris. Bipolar (20 $\mathrm{mm}$ interelectrode distance) surface EMG recording (miniature-sized skin electrodes 650437, Beckman) was employed. The electrodes were placed longitudinally on the motor point areas determined by an electrical stimulator. EMG signals were recorded telemetrically (2000 Glonner, Biomes). EMG was integrated (iEMG, and expressed for one second, $\mu \mathrm{Vs}$ ) for each muscle separately for the maximal peak force phase of the maximal isometric action. The respective maximum iEMG values recorded for the right and left vastus medialis and lateralis during the best maximal leg extension force action were taken for further analysis. ${ }^{27}$ The iEMG of the biceps femoris acting as an antagonist was also recorded during the isometric leg extension action. To calculate the antagonist coactivation percentage for the biceps femoris muscle during the extension actions, the EMG of the biceps femoris acting as an agonist was recorded during the maximal unilateral isometric knee flexion (iEMG of the biceps femoris during extension/iEMG of biceps femoris during flexion $\times 100) .{ }^{28}$
JUMPS

Dynamic explosive force characteristics of the leg muscles were measured on a force platform by using a maximal vertical squat jump (from a starting position of $90^{\circ}$ for the knee angle). The hands were kept on the hips during the jump. The height of rise of the centre of gravity in the squat jump was calculated from the flight time. Three maximal jumps were recorded and the best maximum height was taken for further analysis. In all test conditions the time between maximal contractions or jumps was 1.5 minutes.

\section{SUBJECTIVELY PERCEIVED SYMPTOMS}

Before and after the 21 week follow up period the subjectively perceived and reported intensity of most essential FM symptoms were rated on patients' self administered questionnaires. General pain and pain located in different anatomical parts of the body were expressed using a visual analogue scale, where the end descriptions were $0=$ no pain and $100=$ worst possible pain. In general health the end descriptions were "best-worst possible condition", in sleep "normal sleep - totally unable to sleep", and in fatigue "no fatigue-worst possible fatigue". The Stanford Health Assessment Questionnaire (HAQ) was used for the assessment of physical functional capacity ${ }^{29}$ and the short version of Beck's depression index to assess the mood of the subjects with FM. ${ }^{30}$

\section{EXPERIMENTAL STRENGTH TRAINING}

The training period was 21 weeks. The first four weeks of the study served as a control period. The subjects maintained their ordinary daily chores and physical activities, but no strength training was carried out. Thereafter, women in the $\mathrm{FM}_{\mathrm{T}}$ and $\mathrm{H}_{\mathrm{T}}$ groups started a supervised strength training period. Training was carried out twice a week and each training session included six to eight exercises, such as a squat exercise, knee and trunk extension/flexion exercises, and bench press. During the first three week period strength training was started with 15-20 repetitions for each set with loads of $40-60 \%$ of the one repetition maximum ( $1 \mathrm{RM}$ ) and continued during the next four weeks with 10-12 repetitions for each set with loads of $60-70 \%$ of $1 \mathrm{RM}$. Subsequently, during weeks 8-14 the number of repetitions was $8-12$ for each set with loads of $60-80 \%$ of $1 \mathrm{RM}$, and during the last seven weeks $5-10$ repetitions with loads of $70-80 \%$ of $1 \mathrm{RM}$ were performed. In addition, from the seventh week onwards $30 \%$ of the training for the leg muscles was performed as "explosive" strength training with light loads of 40-60\%, but each repetition was performed as rapidly as possible. All training sessions included warm up and cool down exercises using a bicycle ergometer and muscle stretching. Moreover, the subjects continued their ordinary daily chores and physical activities.

\section{STATISTICS}

The means and standard deviations (SD) are given as descriptive statistics. The performance characteristics of the training groups and the reference group were compared with a one way analysis of variance. To determine the effects of 
strength training the data were analysed by multivariate analysis of variance with repeated measures. The level of statistical significance was $\mathrm{p}<0.05$. The coefficients of correlation were calculated with the Spearman's test.

\section{Results}

The bilateral dynamic (1 RM) and isometric leg extension forces remained statistically unaltered in all study groups during the four week control period (figs 1 and 2). During the 21 weeks of strength training the mean (SD) 1 $\mathrm{RM}$ values increased in $\mathrm{FM}_{\mathrm{T}}$ by 23 (6)\% $(\mathrm{p}<0.001)$, in $\mathrm{H}_{\mathrm{T}}$ by $28(9) \%(\mathrm{p}<0.001)$, while a slight (NS) decrease of 1 (3)\% occurred in $\mathrm{FM}_{\mathrm{C}}$ (fig 1). The mean (SD) maximal bilateral isometric leg extension strength increased by $27(11) \%(\mathrm{p}<0.001), 37(16) \%(\mathrm{p}<0.001)$, and $7(9) \%(\mathrm{NS})$ in $\mathrm{FM}_{\mathrm{T}}, \mathrm{H}_{\mathrm{T}}$, and $\mathrm{FM}_{\mathrm{C}}$, respectively (fig 2). The difference in the changes of isometric leg extension forces between $\mathrm{FM}_{\mathrm{T}}$ and $\mathrm{FM}_{\mathrm{C}}$ and between $\mathrm{H}_{\mathrm{T}}$ and $\mathrm{FM}_{\mathrm{C}}$ were significant $(p<0.001)$.

None of the groups showed statistically significant changes during the control period in the maximal agonist iEMGs of the vastus lateralis and vastus medialis muscles of the bilateral isometric leg extension actions (fig 3). During the 21 week training period the iEMGs of the

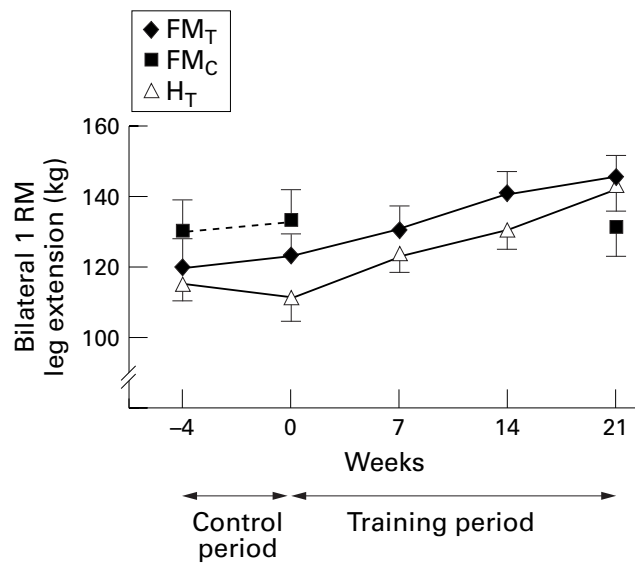

Figure 1 Mean (SD) bilateral leg extension (1 RM) in fibromyalgia $\left(F M_{T}\right)$ and healthy $\left(H_{T}\right)$ trainers and fibromyalgia controls $\left(F M_{C}\right)$ during the four week control and 21 week strength training periods.

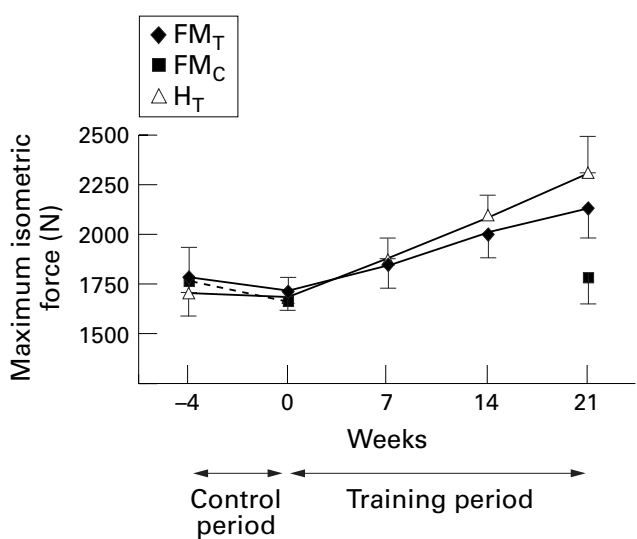

Figure 2 Mean (SD) bilateral isometric leg extension forces in fibromyalgia $\left(F M_{T}\right)$ and healthy $\left(H_{T}\right)$ trainers and fibromyalgia controls $\left(F M_{C}\right)$ during the four week control and 21 week strength training periods. right and left legs increased significantly in $\mathrm{H}_{\mathrm{T}}$ $(p=0.002$ and $p<0.001)$ and in $\mathrm{FM}_{\mathrm{T}}(\mathrm{p}=0.008$ and $\mathrm{p}<0.001$ ). In $\mathrm{FM}_{\mathrm{C}}$ only minor $(\mathrm{NS})$ changes were recorded. At the post-test the difference of the changes between the $\mathrm{FM}_{\mathrm{T}}$ and $\mathrm{FM}_{\mathrm{C}}$ groups and the $\mathrm{H}_{\mathrm{T}}$ and $\mathrm{FM}_{\mathrm{C}}$ groups was significant $(p=0.023$ and $p=0.013)$, respectively. The coactivation of the biceps femoris during the isometric leg extension did not change statistically significantly in any of the groups during either the four week control period or the 21 week experimental period (fig 4).

The mean (SD) maximal rate of the rise of force development (RFD) did not change
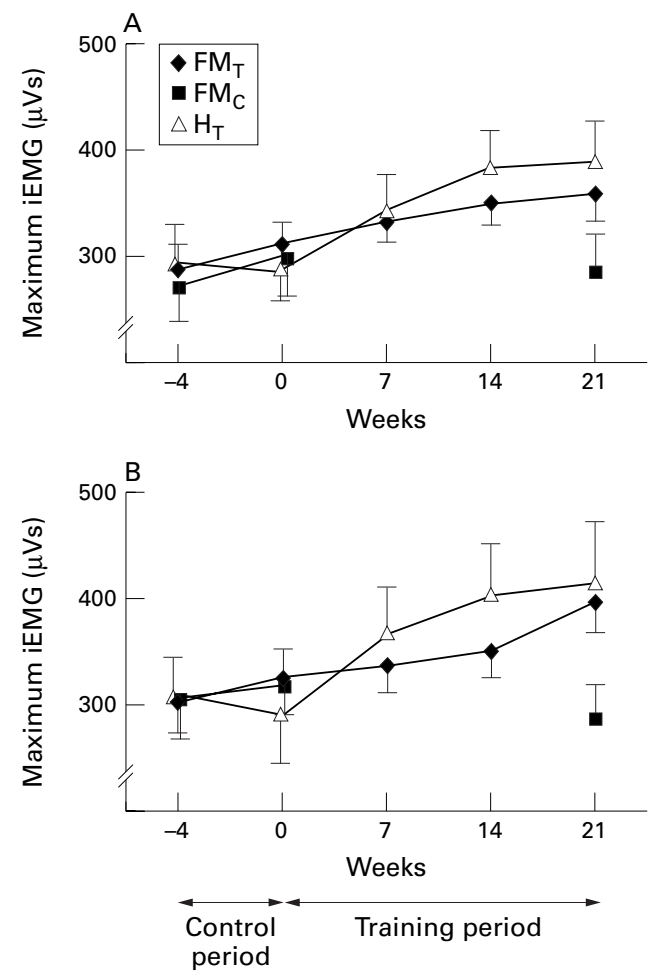

Figure 3 Mean (SD) maximal integrated electromyographic (iEMG) activity of the vastus medialis and vastus lateralis muscles in maximal isometric leg extension in fibromyalgia $\left(F M_{T}\right)$ and healthy $\left(H_{T}\right)$ trainers and fibromyalgia controls $\left(F M_{C}\right)$ during the four week control and 21 week strength training periods. (A) left leg; (B) right leg.

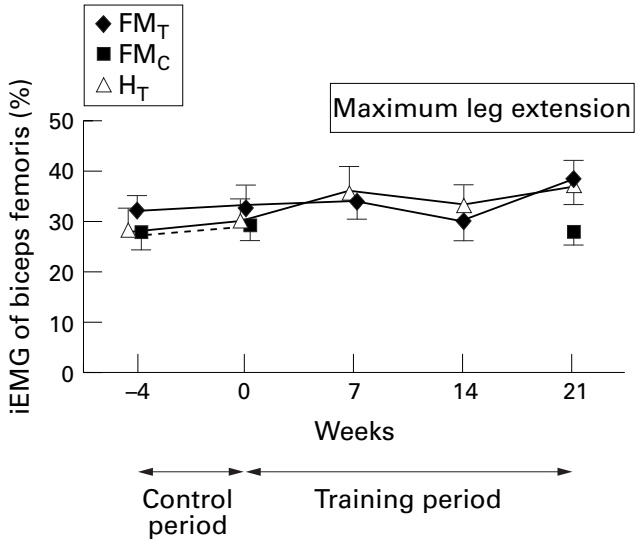

Figure 4 Coactivation percentage of the biceps femoris muscle during maximal isometric leg extension in fibromyalgia $\left(F M_{T}\right)$ and healthy $\left(H_{T}\right)$ trainers and fibromyalgia controls $\left(F M_{C}\right)$ during the four week contro and 21 week strength training periods. 


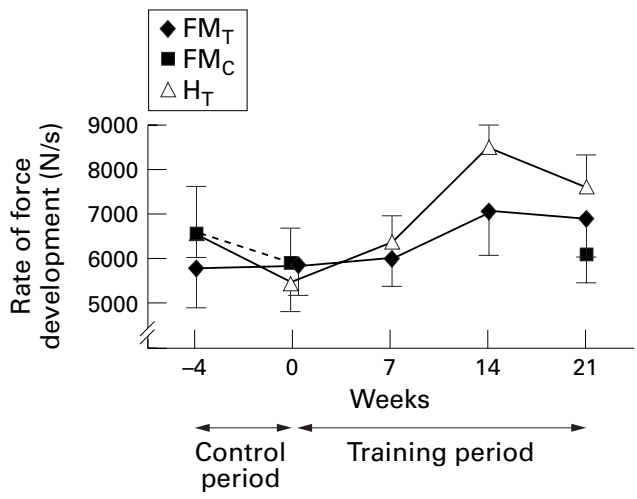

Figure 5 Mean (SD) maximal rate of force development in bilateral isometric leg extension in fibromyalgia (FM ${ }_{T}$ ) and healthy $\left(H_{T}\right)$ trainers and fibromyalgia controls $\left(F M_{C}\right)$ during the four week control and 21 week strength training periods.

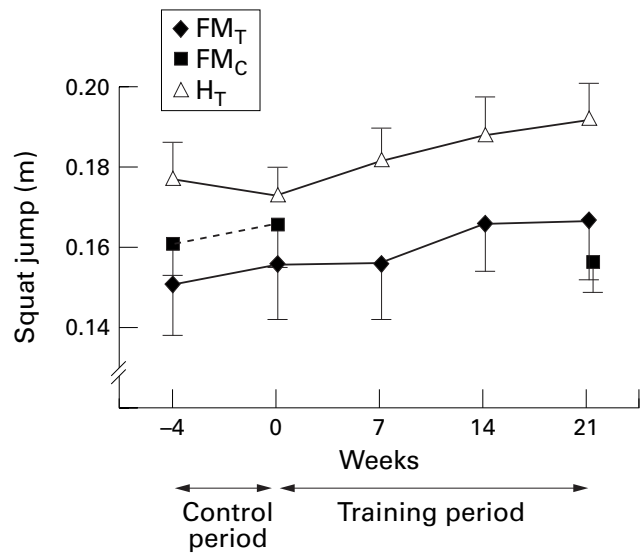

Figure 6 Mean heights (SD) in maximal vertical squat jump among fibromyalgia $\left(F M_{T}\right)$ and healthy $\left(H_{T}\right)$ trainers and fibromyalgia controls $\left(F M_{C}\right)$ during the four week control and 21 week strength training periods.

significantly during the control period in any of the three groups (fig 5). The RFD values were at their highest after 14 weeks of training both in the $\mathrm{H}_{\mathrm{T}}(\mathrm{p}=0.017)$ and $\mathrm{FM}_{\mathrm{T}}(\mathrm{p}=0.013)$ groups in comparison with baseline and then decreased slightly (NS) during weeks 14-21. The RFD values remained unchanged in $\mathrm{FM}_{\mathrm{C}}$.

The maximal vertical heights in the squat jump remained statistically unaltered in all groups during the control period (fig 6). During the 21 week training period the squat jump height increased in $\mathrm{FM}_{\mathrm{T}}$ by 12 (10)\%

Table 2 Subjectively perceived symptoms (mean (SD)) in the training $\left(F M_{T}\right)$ and non-training $\left(F M_{C}\right)$ women with fibromyalgia before and after the 21 week study period

\begin{tabular}{|c|c|c|c|c|}
\hline & \multicolumn{2}{|c|}{$F M_{T}(n=11)$} & \multicolumn{2}{|c|}{$F M_{C}(n=10)$} \\
\hline & Before & After & Before & After \\
\hline General pain (VAS $\neq, 0-100 \mathrm{~mm}$ ) & $48(25)$ & $24(19)$ & $35(19)$ & $60(27)$ \\
\hline \multicolumn{5}{|l|}{ Pain in different parts of the body: } \\
\hline Back & $37(32)$ & $28(24)$ & $35(32)$ & $52(29)$ \\
\hline Neck & $45(19)$ & $22(29)^{\star}$ & $56(33)$ & $51(35)+$ \\
\hline Abdomen & $15(15)$ & $23(26)$ & $22(25)$ & $31(32)$ \\
\hline Arms & $56(26)$ & $36(24)$ & $61(30)$ & $36(34)$ \\
\hline Legs & $40(21)$ & $46(26)$ & $64(30)$ & $61(31)$ \\
\hline General health (VAS, $0-100 \mathrm{~mm}$ ) & $53(26)$ & $27(22)$ & $34(29)$ & $48(26)$ \\
\hline Sleep (VAS, $0-100 \mathrm{~mm}$ ) & $47(23)$ & $37(14)$ & $58(29)$ & $55(22)$ \\
\hline Fatique (VAS, $0-100 \mathrm{~mm}$ ) & $62(22)$ & $43(25)^{\star}$ & $59(31)$ & $60(22)$ \\
\hline HAQ $\ddagger$ disability $(0-3)$ & $0.6(0.6)$ & $0.3(0.6)$ & $0.7(0.4)$ & $0.7(0.3)$ \\
\hline Depression index ( $0-21$ points) & $6.4(5.0)$ & $3.6(3.1)^{\star}$ & $6.6(4.9)$ & $7.5(4.9) \dagger$ \\
\hline
\end{tabular}

${ }^{\star} \mathrm{p}<0.05$, change within the group between before and after the test. $t p<0.05$, difference between the groups after the test.

$\mp$ VAS = visual analogue scale; $\mathrm{HAQ}=$ Health Assessment Questionnaire
( $\mathrm{p}=0.005)$, in $\mathrm{H}_{\mathrm{T}}$ by $11(13) \%(\mathrm{p}=0.007)$ while in $\mathrm{FM}_{\mathrm{C}}$ it decreased by $4(20) \%$ (NS). The differences in the relative changes between $\mathrm{FM}_{\mathrm{T}}$ and $\mathrm{FM}_{\mathrm{C}}$ and between $\mathrm{H}_{\mathrm{T}}$ and $\mathrm{FM}_{\mathrm{C}}$ were significant $(\mathrm{p}=0.003$ and $\mathrm{p}=0.026$, respectively).

At the beginning of the trial the perceived symptoms were similar in both FM groups (table 2). After the 21 week strength training period neck pain, fatigue, and depression indices improved significantly in $\mathrm{FM}_{\mathrm{T}}$. In $\mathrm{FM}_{\mathrm{C}}$ none of the changes was significant. Neck pain and depression indices were more favourable in the $\mathrm{FM}_{\mathrm{T}}$ group than in the $\mathrm{FM}_{\mathrm{C}}$ group after the test. There was a positive correlation between general health and general pain both in the $\mathrm{FM}_{\mathrm{T}}\left(r_{s}=0.87 ; \mathrm{p}<0.001\right)$ and $\mathrm{FM}_{\mathrm{C}}\left(r_{s}=0.93\right.$; $\mathrm{p}<0.001)$ groups at the post-test. In the $\mathrm{FM}_{\mathrm{T}}$ group the change of depression index correlated positively with the change of fatigue $\left(r_{s}=0.66 ; \mathrm{p}=0.036\right)$, and HAQ index changes correlated positively with the changes of general pain $\left(r_{s}=0.95 ; \mathrm{p}=0.004\right)$ and general health $\left(r_{s}=0.86 ; \mathrm{p}=0.027\right)$.

\section{Discussion}

This study showed that during the 21 week progressive strength training female patients with FM could increase their maximal dynamic and isometric muscle strength to the same extent as healthy women. The strength gains in both $\mathrm{FM}_{\mathrm{T}}$ and $\mathrm{H}_{\mathrm{T}}$ groups were accompanied by considerable increases in the maximal voluntary neural activation of the agonist vastus medialis and vastus lateralis muscles. The performance in the squat jump increased significantly in both training groups as did the changes in explosive strength of the leg extensors recorded in the isometric action (RFD). Moreover, the progressive strength training showed positive effects in the training women with $\mathrm{FM}\left(\mathrm{FM}_{\mathrm{T}}\right)$ on subjectively perceived fatigue, mood, and neck pain. In the non-training women with $\mathrm{FM}\left(\mathrm{FM}_{\mathrm{C}}\right)$ the measured muscle strength characteristics and perceived symptoms remained unaltered.

It has been shown that in previously untrained healthy people the increases in maximal strength seen during the first weeks of strength training are largely attributable to the increased motor unit activation of the trained agonist muscles. ${ }^{31}{ }^{32}$ In accordance with this, in the present follow up study both $\mathrm{FM}_{\mathrm{T}}$ and $\mathrm{H}_{\mathrm{T}}$ groups showed increases in their maximal isometric force and iEMG during the training period induced by strength training. The increase of iEMG took place not only during the initial weeks but throughout the entire training period, probably owing to the applied training programme with progressively increasing loads throughout the experimental period. Increases in the magnitude of iEMG, induced by strength training, suggest that the number of motor units recruited has increased, or motor units are firing at higher rates, or a combination of these two has occurred. ${ }^{28}{ }^{31}{ }^{32}$ Nevertheless, the increased iEMGs indicate that the contributing role of the nervous system for strength development was important throughout the entire training period. Therefore, the force and 
iEMG increases obtained in $\mathrm{FM}_{\mathrm{T}}$ women can be considered as normal neuromuscular adaptations to strength training stimuli. To what extent the increase in strength might be explained by training induced hypertrophy of the leg extensor muscles was not examined.

The magnitude of the coactivation of the antagonist hamstring muscles during the maximal isometric leg extension was similar in all groups at baseline. This result is consistent with an earlier report ${ }^{25}$ and indicates that the coactivation of these muscle groups was already, at baseline, within the normal range not only in the healthy women but also in the women with FM in both study groups. The present data also indicate the presence of a normal neural inhibitory mechanism aimed at protecting the musculoskeletal system from injury when the agonist muscles become fully activated. ${ }^{25}$ These results further show that the magnitude of the antagonist coactivation remains rather stable not only among middle aged healthy subjects but also among patients with FM, at least when the present type of force production action is applied. Strength training does not produce any further changes in the antagonist coactivation to influence the net strength production of the agonist muscles, but large neural adaptation takes place in the activation of these muscles.

The strength training programme applied was expected to produce increases both in maximal strength and rapid force production of the trained muscles. The ability of muscles to produce force rapidly is important in several tasks of daily life, such as climbing stairs or prevention of falls. The results show that the increases in maximal strength were accompanied by increases in explosive strength characteristics recorded during isometric (RFD) and dynamic (squat jump) actions both in the $\mathrm{FM}_{\mathrm{T}}$ and $\mathrm{H}_{\mathrm{T}}$ groups. This might be explained by the increased rapid neural activation of the trained muscles, ${ }^{28}$ as one third of the exercises were conducted with slightly lower loads but with higher movement velocities in order to improve explosive strength. However, both training groups reached a plateau after 14 weeks of progressive strength training in both RFD and squat jump. The findings indicate a need for more individual programming of the training to optimise the improvement of explosive strength and to maintain it.

Physical exercise has been found to be an effective intervention strategy for long term management of FM. McCain et $a l^{17}$ and Wigers et $a l^{16}$ found that aerobic physical exercise improves not only the cardiovascular fitness but also raises the pain threshold scores of trained patients with FM. In our strength training intervention no statistically significant changes were seen in the number of tender points during the 21 week follow up time, supporting the earlier suggestion that tender point counts are only weakly related to symptom severity. ${ }^{33}$ All the outcome variables of the $\mathrm{FM}_{\mathrm{T}}$ group improved, except for pain in the legs. The training programmes included more exercises for the legs, and training induced muscle soreness may in part explain the finding. On the other hand, the patients with FM had a wide distribution of symptoms and thus only the improvements in neck pain, fatigue, and mood reached statistical significance during the study period. In the $\mathrm{FM}_{\mathrm{T}}$ group the improvements in pain and general health led also to improvements in daily physical function. Thus the subjectively perceived physical disability decreased together with decreasing pain. The result is consistent with that of Hawley et $a l,{ }^{34}$ indicating that functional disability assessed by the HAQ index contributed to the severity of FM.

The improvements in depression index correlated positively with the improvements of fatigue in $\mathrm{FM}_{\mathrm{T}}$. However, the depression index seemed to be unrelated to pain in both FM groups. This result is in line with the results by Baumstark et al showing that depression does not predict pain behaviour among patients with FM. $^{35}$

Despite a rather small study group the results of our supervised strength training study indicate that the neuromuscular system of women with FM and of age matched healthy women can be similarly trained. The evidence supports the suggestion of Simms that FM is a chronic pain syndrome which has a central rather than a peripheral or muscular basis. ${ }^{36}$ Moreover, the improvements in perceived symptoms and function support the assumption that even heavy resistance strength training can safely be used in the treatment of patients with FM to minimise the effects on the neuromuscular system of the inactivity associated with the FM syndrome. Depending on practical conditions group programmes may also be used and sometimes preferred to the above individual exercise regimens as they are financially more feasible. However, owing to the multidimensional nature of FM, various other scientifically effective means, in addition to physical activity, have to be used in the treatment of these patients.

This study was supported in part by grants from Finnish Social Insurance Institution and the Yriö Jahnsson Foundation.

1 Doherty M, Jones A. ABC of rheumatology. Fibromyalgia syndrome. BMJ 1995;310:386-9.

2 Bengtsson A, Henriksson K-G, Larsson J. Reduced high-energy phosphate levels in the painful muscles of patients with fibromyalgia. Arthritis Rheum 1986;29:81721.

3 Bartels E, Danneskiols-Samsoe B. Histological abnormalities in muscle from patients with certain type of fibrositis. Lancet 1986;i:755-7.

4 Park J, Phothimat P, Oates C, Hernanz-Schulman M, Olsen N. Use of P-31 magnetic resonance spectroscopy to detect metabolic abnormalities in muscles of patients with metabolic abnormalities in muscles of patient

5 Simms R, Roy S, Hrovat M, Anderson J, Skinnar G,

Simms R, Roy S, Hrovat M, Anderson J, Skinnar G,
LePoole S, et al. Lack of association between fibromyalgia syndrome and abnormalities in muscle energy metabolism. syndrome and abnormalities in musc

Arthritis Rheum 1994;37:794-800.
6 de Blecourt A, Wolf R, van Rijswijk M, Kamman R, Knipping A, Mooyaart A. In vivo ${ }^{31} \mathrm{P}$ magnetic resonance spectroscopy (MRS) of tender points in patients with primary fibromyalgia syndrome. Rheumatol Int 1991;11: 51-4

7 Clark S, Tindall E, Bennett R. A double blind crossover trial of prednisolone versus placebo in the treatment of fibrositis. J Rheumatol 1985;12:980-3.

8 Goldenberg D, Felson D, Dinerman H. A randomized controlled trial of amitriptyline and naproxen in the treatment of patients with fibromyalgia. Arthritis Rheum 1986;29: 655-9.

9 Pattrick M, Swannell A, Doherty M. Chlormezanone in primary fibramyalgia syndrome: a double blind placebo mary fibramyalgia syndrome: a double blind pla

10 Drewes A, Andreasen A, Jennum P, Nielsen K. Zopiclone in the treatment of sleep abnormalities in fibromyalgia. Scand J Rheumatol 1991;20:288-93. 
11 Moldowsky H, Lue F, Mously C, Roth-Schechter B, Reynolds W. The effect of zolpidem in patients with fibromyalgia: a dose rangin led, modified crossover study. J Rheumatol 1996;23:529-

12 Wolfe F, Cathey M, Harwey D. A double-blind placebo controlled trial of fluoxetine in fibromyalgia. Scand J Rheumatol 1994;23:255-9.

13 Norregaard J, Volkmann H, Danneskiold-Samsoe B. A randomized controlled trial of citalopram in the treatment of fibromyalgia. Pain 1995;61:445-9.

14 Hannonen P, Malminiemi K, Yli-Kerttula U, Isomeri R, Roponen P. A randomized, double-blind, placebo controlled study of moclobemide and amitriptyline in the treatment of fibromyalgia in females without psychiatric disorder. Br J Rheumatol 1998;37:1279-86.

15 Jaeshe R, Adachi J, Guyatt G, Keller J, Wong B. Clinical usefulness of amitriptyline in fibromyalgia. The results of 23 N-of-1 randomized controlled trials. J Rheumatol 1991; 18:447-51.

16 Wigers S, Stiles T, Vogel P. Effects of aerobic exercise versus stress management in fibromyalgia. A 4.5 year prospective stress management in fibromyalgia. A 4.5

17 McCain G, Bell D, Mai F, Halliday P. A controlled study of the effects of a supervised cardiovascular fitness training program on the manifestations of primary fibromyalgia. Arthritis Rheum 1988;31:1135-41.

18 Mengshoel A, Komnaes H, Forre O. The effects of 20 weeks of physical training in female patients with fibromyalgia Clin Exp Rheumatol 1992;10:345-9.

19 Buchelev S, Convay R, Parker J, Deuser W, Read J, Witty T, et al. Biofeedback/relaxation training and exercise interventions for fibromyalgia: a prospective trial. Arthritis Care and Research 1998;11:196-209.

20 Ferraccioli G, Ghirelli L, Scita F, Nolli M, Mozzani M, Fontana $\mathrm{S}$, et al. EMG-biofeedback training in fibromyalgia syndrome. J Rheumatol 1987;14:820-5.

21 Martin L, Nutting A, MacIntosh B, Edworthy S, Buttenwick D, Cook J. An exercise program in the treatment of wick D, Cook J. An exercise program in the
fibromyalgia. J Rheumatol 1996;23:1050-3.

22 Bennett R, Buckhardt C, Clark S, O'Reilly C, Wiens A Campbell S. Group treatment of fibromyalgia. A 6 month

23 Nielson W, Walker C, McCain G. Cognitive behavioural treatment of fibromyalgia syndrome. Preliminary findings. J Rheumatol 1992;19:98-103.

24 Wolfe F, Smythe H, Yunus M, Bennett R, Bombardier C, Goldenberg D, et al. The American College of Rheumatol- ogy 1990 criteria for the classification of fibromyalgia. Report of the multicenter criteria committee. Arthritis Rheum 1990;33:160-72.

25 Häkkinen $\mathrm{K}$, Alen $M$, Kallinen $M$, Izquierdo $M$, Jokelainen $\mathrm{K}$, Lassila $\mathrm{H}$, et al. Muscle CSA, force production, and activation of leg extensors during isometric and dynamic actions in middle-aged and elderly men and women. Journal of Ageing and Physical Activity 1998;6:232-47.

26 Häkkinen K, Komi P, Kauhanen H. Scientific evaluation of specific loading of the knee extensors with variable resistance, isokinetic and barbell exercises. In: Marconnet P, Komi P, eds. Medicine and sport science. Basel: Kargel, 1987:224-37.

27 Häkkinen $\mathrm{K}$, Alen M, Komi P. Changes in isometric forceand relaxation time, electromyographic and muscle fiber characteristics of human skeletal muscle during strength characteristics of human skeletal muscle during strength trainin.

28 Häkkinen $\mathrm{K}$, Kallinen $M$, Izquierdo $M$, Jokelainen $\mathrm{K}$, Mälkiä E, Kraemer W, et al. Changes in agonist-antagonist EMG, muscle CSA, and force during strength training in middle-aged and older people. J Appl Physiol 1998;84: 1341-9.

29 Fries J, Spitz P, Kraines R, Holman H. Measurements of patient outcome in arthritis. Arthritis Rheum 1980;23. $137-45$.

30 Beck A, Ward C, Mendelson M, Mock J, Erlbaugh J. An inventory for measuring depression. Arch Gen Psychiatry 1961;4:561-71.

31 Moritani T, DeVries H. Neural factors versus hypertrophy in the time course of muscle strength gain. Am J Phys Med 1979;58:115-30.

32 Häkkinen K, Komi P. Electromyographic changes during trength training and detraining. Med Sci Sports Exerc 1983;15:455-60.

33 Jacobs J, Rasker J, van der Heijde A, Boersma J, de Blecourt A, Griep E, et al. Lack of correlation between the mean tender point score and self reported pain in fibromyalgia. Arthritis Care and Research 1996;9:105-11.

34 Hawley D, Wolfe F, Cathey M. Pain, functional disability and psychological status: a 12-month study of severity in fibromyalgia. J Rheumatol 1988;15:1551-6.

35 Baumstark K, Buchelev S, Sher K, Beck N, Buescher K, Hewett J, et al. Pain behaviour predictors among fibromyalgia patients. Pain 1993;55:339-46.

36 Simms R. Fibromyalgia is not a muscle disorder. Am J Med Sci 1998;315:346-50. 